\title{
Chemotherapeutics in the treatment of multiple sclerosis
}

\author{
Bernd C. Kieseier and Douglas R. Jeffery
}

Abstract: The likely pathogenic mechanisms of multiple sclerosis (MS) provide a sound rationale for investigating the efficacy of drugs possessing immunosuppressive or immunomodulatory properties. With proven efficacy, safety and tolerability, interferon beta formulations and glatiramer acetate have become the mainstay of initial treatment for patients with relapsing forms of MS. More recently, natalizumab, a humanized monoclonal antibody (mAb) against the cellular adhesion molecule $\alpha 4$-integrin, has been employed for patients with an inadequate response or lack of tolerability to an alternate MS therapy, or as initial therapy for patients with severe disease. Various agents initially developed for oncological indications, either as chemotherapeutics or mAbs, may also have current or future uses in MS treatment. Mitoxantrone is currently the only chemotherapeutic agent approved for treatment of MS in the United States, while in parts of Europe azathioprine is approved and widely used for MS treatment. Other chemotherapeutics that have been tested in MS to date include cyclophosphamide, methotrexate, cladribine, and the mAbs alemtuzumab and rituximab. While there has been varying evidence of efficacy for these compounds, each appears to be associated with serious risks that require careful consideration and management. Given the risks that have been demonstrated for available chemotherapeutic agents and while long-term postmarketing safety data are still not available for those agents in development, it seems prudent to carefully assess the possible use of chemotherapeutics in the treatment of MS. A thorough risk-benefit analysis is becoming increasingly important in the assessment of therapeutic options for this disabling disease.

Keywords: chemotherapeutic, glatiramer acetate, immunomodulatory, immunosuppressive, interferon beta, multiple sclerosis, risk-benefit, toxicity

\section{Introduction}

Multiple sclerosis (MS) is a chronic inflammatory demyelinating disease of the central nervous system (CNS) that affects more than 1 million people worldwide, and is one of the most frequent neurologic disorders in young adults [Noseworthy et al. 2000]. As a consequence of the considerable physical and psychological burden of the neurological deficits that occur as a result of MS, patients may find their working life prematurely limited, be at risk of hospitalization during severe exacerbations, and may need assistance to support their normal activities of daily living.

The likely pathogenic mechanisms of MS provide sound rationale for investigating the efficacy of drugs possessing immunosuppressive properties (e.g. ability to inhibit $\mathrm{T}$ helper [Th1] cells, $B$ cells, and macrophages) or immunomodulatory effects (e.g. ability to inhibit inflammatory cytokines). Consequently, certain chemotherapeutic agents with immunosuppressive properties that were originally approved for the treatment of malignancies and used in the setting of transplantation have been, or are being, investigated for the management of MS (Table 1).

\section{Pathogenesis of MS}

A wealth of research and clinical experience suggests that the development of MS is associated with both inflammatory and neurodegenerative processes. Early in the disease course, the environment, genetics, and infective processes may all play a role in activating proinflammatory Th 1 cells in the periphery [The International
Ther Adv Neurol Disord

(2010) 3(5) 277-291

DOI: $10.1177 /$

1756285610379885

(C) The Author(s), 2010 Reprints and permissions:

http://www.sagepub.co.uk/ journalsPermissions.nav
Correspondence to: Bernd C. Kieseier, MD Department of Neurology, Heinrich-Heine University, Moorenstrasse 5, 40225 Düsseldorf, Germany bernd.kieseierla uni-duesseldorf.de Douglas R. Jeffery, MD, PhD

Department of Neurology, Wake Forest University, Winston-Salem, NC, USA 
Table 1. Chemotherapeutics in multiple sclerosis: mechanism of action, current indications, and stage of development in multiple sclerosis.

\begin{tabular}{ll}
\hline Mechanism of action \\
\hline Alemtuzumab & Humanized mAb directed \\
& against the CD52 antigen \\
& expressed on the cell surface \\
of both T and B lymphocytes, \\
monocytes, macrophages, and \\
eosinophils, but not stem \\
cells. It depletes target anti- \\
gen carrying cells
\end{tabular}

Use in oncology

- Treatment of refractory chronic lymphocytic leukemia

\section{Azathioprine}

Cladribine

Cyclophosphamide

Methotrexate

Mitoxantrone

Rituximab
- Purine analog metabolized rapidly to cytotoxic and immunosuppressant derivatives 6-mercaptopurine and thioinosine acid. Mainly targets activation, proliferation, and differentiation of both $T$ and $B$ lymphocytes by competition of its metabolites with DNA nucleotides

- Adenosine deaminase-resistant nucleoside analog that preferentially depletes subpopulations of lymphocytes. Cladribine triphosphate becomes incorporated into DNA in dividing cells, leading to DNA damage and subsequent cell death

- Alkylating agent related to nitrogen mustards and its active metabolites induce DNA string breaks. Can also shift immune responses from Th1 cells toward Th2 cells by an unknown mechanism

- Antimetabolite that inhibits dihydrofolic acid reductase. Methotrexate interferes with DNA synthesis, repair, and cellular replication

- Acts by intercalating with DNA and inhibiting topoisomerase II. Also potently inhibits B-cell, T-cell, and macrophage proliferation and impairs antigen presentation, as well as the secretion of IFN $\gamma, T N F \alpha$, and IL-2

- Chimeric murine/human mAb that targets and selectively depletes CD20, an antigen present on pre-B cells and $B$ cells but not on antibody-producing plasma cells or stem cells in the bone marrow
- Not used in oncology. Indicated as an adjunct for the prevention of rejection in renal homotransplantation. Also indicated for the management of active rheumatoid arthritis to reduce signs and

- Hairy-cell leukemia and lymphoma

- A variety of malignancies, including malignant lymphomas, multiple myeloma, leukemias, neuroblastoma, retinoblastoma, and breast cancer

- Gestational choriocarcinoma, chorioadenoma destruens, hydatidiform mole, meningeal leukemia, advanced stage nonHodgkin lymphomas, and other malignancies

- Treatment of breast cancer and leukemias, and for patients with pain related to hormone-resistant prostate cancer

- Treatment of non-Hodgkin lymphoma, refractory rheumatoid arthritis, and diffuse B-cell lymphoma symptoms
Stage of development in MS

- Not approved for the treatment of MS. Promising initial efficacy findings were observed in the phase II CAMMS223 trial. However, considerable toxicity was also observed. The risk-benefit profile of alemtuzumab is currently being further assessed

- Not approved for the treatment of MS in US, approved in Germany. Promising MS efficacy data versus IFN $\beta$. Safety concerns for occurrence of non-Hodgkin lymphoma or other malignancies with chronic use

- Not approved for the treatment of MS. Promising initial efficacy findings were observed in the phase III CLARITY trial. The risk-benefit profile of oral cladribine is currently being further assessed in several ongoing clinical studies and through a safety registry

- Not approved for the treatment of MS. Trials in MS have been inconclusive

- Not approved for the treatment of MS. Trials in MS have been inconclusive

- Approved for reducing neurologic disability and/or the frequency of clinical relapses in patients with SPMS, PRMS, or worsening RRMS

- Mixed findings in MS. Development of rituximab in MS has been discontinued

MS, multiple sclerosis; mAb, monoclonal antibody; IFN, interferon; TNF, tumor necrosis factor; IL, interleukin; SPMS, secondary progressive MS; PRMS, progressive relapsing MS; RRMS, relapsing-remitting MS. 
Multiple Sclerosis Genetics Consortium, 2007; Gilden, 2005; Noseworthy et al. 2000]. These activated cells then infiltrate the CNS by crossing the blood-brain barrier (BBB) and thereafter release a variety of proinflammatory cytokines [Noseworthy et al. 2000; van Boxel-Dezaire et al. 1999; Yong et al. 1998; Arnason et al. 1996]. The release of proinflammatory cytokines is associated with a decrease in anti-inflammatory processes [van Boxel-Dezaire et al. 1999], an increase in the secretion of toxic free radicals and increased oxidative stress [Gonsette, 2008; Rejdak et al. 2008; Platten and Steinman, 2005], and the recruitment of macrophages and certain B cells [Racke, 2008; Noseworthy et al. 2000]. These various processes lead to localized areas of demyelination, and oligodendrocyte and axonal loss [Noseworthy et al. 2000]. The resulting neurodegenerative lesions accumulate over time and promote progressive increases in disease burden and disability.

\section{Current management of relapsing-remitting multiple sclerosis}

Interferon beta (IFN $\beta$ ) formulations and glatiramer acetate (GA) have been the mainstay of initial treatment for patients with relapsing forms of MS. The effects of IFN $\beta$ on immune cell targets in MS have been shown to include reducing antigen presentation and T-cell proliferation, altering cytokine and matrix metalloproteinase (MMP) expression, and restoring suppressor cell functions [Markowitz, 2007]. Similarly, GA appears to alter disease expression in MS by generating suppressor cells, inducing tolerance, expanding regulatory T-cell populations, and altering antigen presenting cells [Racke et al. 2010]. IFN $\beta$ and GA have shown efficacy in preventing relapses and delaying disease progression [Kappos et al. 2007, 2006; Kinkel et al. 2006; Vartanian, 2003; Comi et al. 2001a, 2001b; PRISMS Study Group, 1998; Jacobs et al. 1996; Johnson et al. 1995; The IFN $\beta$ Multiple Sclerosis Study Group and the University of British Columbia MS/MRI Analysis Group, 1995].

Natalizumab is the first of the new generation of agents for the treatment of MS. It is a humanized monoclonal antibody $(\mathrm{mAb})$ that targets the $\alpha 4$-integrin, thereby interfering with the infiltration of activated $\mathrm{T}$ cells across the BBB into the CNS. Results from clinical trials with natalizumab show a larger reduction in the annualized relapse rate (ARR) than with IFN $\beta$ and GA in treatment-naive patients [Polman et al. 2006; Rudick et al. 2006]. However, it is generally recommended for use in patients who do not respond to, or who cannot tolerate, other therapies because it is associated with an increased risk of progressive multifocal leukoencephalopathy (PML), a rare, opportunistic, viral brain infection that may lead to death or severe disability [Clifford et al. 2010]. Natalizumab is used as a first-line treatment in patients with more severe disease activity. Data from the pivotal trials have shown that natalizumab is effective irrespective of patient demographic and MS disease characteristics and appears to provide greater efficacy in patients with highly active disease [Hutchinson et al. 2009; Kieseier et al. 2009].

\section{Treatment options for patients who do not respond to initial therapy}

Many patients have a suboptimal response to first-line treatment with GA or IFN $\beta$. Observations from phase III studies in relapsing-remitting MS (RRMS) indicate that as many as two thirds of patients experienced a relapse during the first 2 years of treatment [PRISMS Study Group, 1998; Jacobs et al. 1996; Johnson et al. 1995; The IFN $\beta$ Multiple Sclerosis Study Group and the University of British Columbia MS/MRI Analysis Group, 1995]. There are a few options for patients not responding adequately to initial treatment with IFN $\beta$ or GA.

There is limited evidence that switching among first-line therapies is effective for patients who do not respond to their initial therapy. Some investigators have reported that $56-73 \%$ of patients were relapse free at 3 years after switching from either GA to IFN $\beta$ ( $9 / 16$ patients) or vice versa (38/52 patients) because of suboptimal response or adverse events with initial treatment [Carrá et al. 2008]. While common in other inflammatory conditions such as rheumatoid arthritis, efficacy data to support combining immunomodulatory agents to optimize MS treatment remain limited [Gold, 2008; Fernandez, 2007]. Switching to potentially more effective therapy such as natalizumab [Rudick et al. 2006] or using a chemotherapeutic agent (e.g. mitoxantrone, cyclophosphamide) represent other options.

Given that MS currently remains incurable and the therapies discussed above do not completely prevent disease progression in most patients, 
there is an unmet need for effective alternative treatment options in MS. The final option noted above for managing patients who do not respond to initial therapy has been to use a chemotherapeutic agent. The current, and possible future, roles of chemotherapeutic agents in the management of MS are discussed in the remainder of this review.

\section{Chemotherapeutic agents approved for the management of multiple sclerosis}

\section{Mitoxantrone}

Mitoxantrone is currently the only US Food and Drug Administration (FDA)-approved chemotherapeutic agent for the treatment of MS. Originally developed in the 1970s, mitoxantrone is a cytotoxic agent of the anthracenedione family that acts by intercalating with DNA and inhibiting topoisomerase II. It is widely used for the treatment of breast cancer and leukemias, and for patients with pain related to hormone-resistant prostate cancer [Novantrone (mitoxantrone) US prescribing information, 2009]. It has also been shown to have immunosuppressive and immunomodulatory properties. In vitro, mitoxantrone inhibits B-cell, T-cell, and macrophage proliferation and impairs antigen presentation as well as the secretion of IFN $\gamma$, tumor necrosis factor alpha (TNF $\alpha)$, and interleukin-2 (IL-2) [Novantrone (mitoxantrone) US prescribing information, 2009; Kopadze et al. 2006; Chan et al. 2005; Neuhaus et al. 2005]. As well as being used as an antineoplastic agent, mitoxantrone is indicated for reducing neurologic disability and/or the frequency of clinical relapses in patients with secondary progressive MS (SPMS), progressive relapsing MS (PRMS), or worsening RRMS [Novantrone (mitoxantrone) US prescribing information, 2009].

\section{Efficacy and safety of mitoxantrone monotherapy for treating multiple sclerosis}

The effectiveness of mitoxantrone for the treatment of MS as either a monotherapy or in combination with a corticosteroid has been demonstrated in four randomized, controlled clinical trials, which are summarized in Table 2 [Krapf et al. 2005; Hartung et al. 2002; van de Wyngaert et al. 2001; Edan et al. 1997; Millefiorini et al. 1997]. Among these trials, the Italian trial [Millefiorini et al. 1997] and the mitoxantrone in MS (MIMS) trial [Krapf et al. 2005; Hartung et al. 2002] were placebo controlled, the Belgian trial [van de Wyngaert et al.
2001] utilized methylprednisolone as the comparator, while in the French-British trial [Edan et al. 1997] mitoxantrone combined with steroid was compared with steroid alone. The Italian trial restricted enrollment to patients with RRMS, while other trials also included patients with SPMS and/or PRMS. All trials recorded reductions in ARR for the groups receiving mitoxantrone versus control; Expanded Disability Status Scale (EDSS) scores were improved following mitoxantrone treatment in all but the Belgian trial, and all but the MIMS trial recorded clear MRI benefits in patients receiving mitoxantrone. Overall, findings from these trials would suggest that mitoxantrone may provide moderate reductions in disability progression, MRI lesions, and the frequency of relapses in patients with RRMS, SPMS, and PRMS, although data are not entirely consistent. Smaller, nonrandomized studies have also revealed that mitoxantrone may be a suitable option for patients who are failing to adequately respond to their initial MS treatment regimen [Carrá et al. 2008; Zipoli et al. 2008].

The clinical efficacy of mitoxantrone is associated with increased risk of some concerning side effects that are reviewed in the following, including cardiotoxicity, certain blood cancers, and suppression of bone marrow function [Novantrone (mitoxantrone) US prescribing information, 2009; Neuhaus et al. 2006; Morrissey et al. 2005]. Mitoxantrone is also considered a teratogen.

Potentially fatal cardiotoxicity, including decreased ejection fraction and congestive heart failure, can occur during mitoxantrone therapy. This may be seen during treatment or years after cessation of treatment. The risk of cardiotoxicity appears proportional to the total lifetime cumulative dose of the medication and is increased in patients with a history of cardiac disease. As a consequence, all patients receiving mitoxantrone are routinely assessed for any cardiac signs and symptoms (including reduced left ventricular ejection fraction [LVEF]) prior to each dose. The mitoxantrone dose is limited in the face of reduced LVEF and withheld if there is a decrease in LVEF to below the lower limit of normal or if there is a significant reduction in LVEF during treatment. Patients also undergo annual LVEF evaluations after treatment cessation.

In addition to cardiotoxicity, blood cancers, particularly secondary acute myelogenous leukemia, 
Table 2. Mitoxantrone monotherapy in multiple sclerosis: summary of randomized controlled clinical trials.

\begin{tabular}{|c|c|c|c|c|}
\hline & $\begin{array}{l}\text { French-British trial } \\
\text { [Edan et al. 1997] }\end{array}$ & $\begin{array}{l}\text { Italian trial } \\
\text { [Millefiorini et al. } \\
\text { 1997] }\end{array}$ & $\begin{array}{l}\text { MIMS trial } \\
\text { [Krapf et al. 2005; } \\
\text { Hartung et al. 2002] }\end{array}$ & $\begin{array}{l}\text { Belgian trial } \\
\text { [van de Wyngaert } \\
\text { et al. 2001] }\end{array}$ \\
\hline $\begin{array}{l}\text { Clinical course } \\
\text { of MS }\end{array}$ & Active RRMS/SPMS & RRMS & Active RRMS/SPMS & $\begin{array}{l}\text { Worsening } \\
\text { RRMS/PRMS } \\
\text { /SPMS }\end{array}$ \\
\hline Number of patients & 42 & 51 & 194 & 49 \\
\hline Dosage & $\begin{array}{l}\text { MX } 20 \mathrm{mg} \\
\quad \text { (absolute dose) }+ \\
\text { methylprednisolone } 1 \mathrm{~g}\end{array}$ & $\begin{array}{l}8 \mathrm{mg} / \mathrm{m}^{2} \text { body } \\
\text { surface }\end{array}$ & $\begin{array}{l}12 \mathrm{mg} / \mathrm{m}^{2} \text { body } \\
\text { surface }\end{array}$ & $\begin{array}{l}12 \mathrm{mg} / \mathrm{m}^{2} \text { body } \\
\text { surface }\end{array}$ \\
\hline Treatment frequency & Monthly & Monthly & Every 3 months & Every 3 months \\
\hline Treatment duration & 6 months & 12 months & $\begin{array}{l}24 \text { months with } \\
12 \text { month extension }\end{array}$ & 36 months \\
\hline $\begin{array}{l}\text { Progression of disability } \\
\text { at study end } \\
\text { (deterioration of EDSS } \\
\text { score by } \geq 1 \text { point) }\end{array}$ & $\begin{array}{l}5 \%(n=1 / 21) \\
\quad \text { MX group vs. } 29 \% \\
(n=6 / 21) \text { control }\end{array}$ & $\begin{array}{l}7 \%(n=2 / 27) \mathrm{MX} \\
\text { group vs. } 37 \% \\
(n=9 / 24) \text { control }\end{array}$ & $\begin{array}{l}14 \%(6 / 42) \mathrm{MX} \text { group vs. } \\
40 \%(16 / 40) \text { control, at } \\
36 \text { months }\end{array}$ & $\begin{array}{l}\text { No significant } \\
\text { difference }\end{array}$ \\
\hline ARR at study end & $\begin{array}{l}0.7 \mathrm{MX} \text { group } \\
\text { vs. } 3.0 \text { control }\end{array}$ & $\begin{array}{l}0.9 \mathrm{MX} \text { group vs. } \\
2.6 \text { control }\end{array}$ & $\begin{array}{l}0.3 \mathrm{MX} \text { group vs. } \\
0.9 \text { control }\end{array}$ & $\begin{array}{l}0.2 \mathrm{MX} \text { group } \\
\text { vs.1.1 control }\end{array}$ \\
\hline Reduction of MRI lesions & $\begin{array}{l}84 \% \text { reduction of } \\
\text { new } \mathrm{Gd}+\text { lesions } \\
\text { (mean } 1.2 \mathrm{MX} \text { group vs. } \\
7.5 \text { control) } 80 \% \\
\text { reduction of new } \\
\text { T2 lesions (mean } 1.1 \\
\text { MX group vs. } 5.5 \\
\text { control) }\end{array}$ & $\begin{array}{l}52 \% \text { reduction of } \\
\text { new T2 lesions } \\
\text { (mean } 3.5 \mathrm{MX} \\
\text { group vs } 7.3 \text { control) }\end{array}$ & $\begin{array}{l}\text { No reduction in the } \\
\text { number of MRI scans } \\
\text { with positive Gd } \\
\text { enhancement } \\
\text { vs. placebo } \\
\text { (primary MRI outcome) }\end{array}$ & $\begin{array}{l}70 \% \text { reduction in } \\
\text { the number of } \\
\text { Gd+ active } \\
\text { lesions (mean } 6 \\
\text { MX group vs. } 20 \\
\text { control) }\end{array}$ \\
\hline
\end{tabular}

have been associated with mitoxantrone. Consequently, a complete blood count is recommended prior to each dose and each year after mitoxantrone treatment, to monitor for hematologic adverse events. The risk of therapy-related leukemia may be much higher than initial estimates of $0.07 \%$ [Ghalie et al. 2002], with recent data suggesting a rate ranging from $0.3 \%$ [Ellis and Boggild, 2009] to as high as 1 in 135 treated patients (0.74\%) [Martinelli, 2009]. Indeed, a recent American Academy of Neurology review of all available evidence stated that the number needed to harm was 8 for systolic dysfunction and 123 for developing mitoxantrone therapy-related acute leukemia [Marriott et al. 2010]. However, derivation of high incidence rates from studies of small treatment cohorts and heterogeneous treatment regimens (Table 2) and a lack of comprehensive postmarketing surveillance data preclude estimation of a true incidence rate. Bone marrow suppression is a limiting side effect of mitoxantrone, requiring careful clinical management and hematologic monitoring.
Other acute adverse events associated with mitoxantrone include an increased incidence (versus placebo) of nausea, mild alopecia, urinary tract infection, and menstrual disorders. The menstrual disorders can in some cases be permanent but are usually seen in women over the age of 35 years.

Owing to the possibility of various adverse events, mitoxantrone is recommended to be administered by a physician experienced in the use of cytotoxic agents. Mitoxantrone treatment should also be limited to RRMS and SPMS patients with clear evidence of worsening disability, is usually reserved for patients who have not responded sufficiently to, or could not tolerate, IFN $\beta$ and GA, and might also be considered as an agent reserved for use in patients who are not suitable for natalizumab treatment. Because there is little inflammation in the later stages of SPMS, the use of mitoxantrone is generally targeted to patients with early-stage SPMS and ongoing inflammation (i.e. clinical relapses or gadolinium-enhanced lesions on brain MRI). 
The availability of suitable biomarkers that would allow responses to mitoxantrone to be predicted and facilitate some degree of individualized risk stratification would be useful clinical tools for the use of mitoxantrone in MS patients. ATP-binding cassette $(\mathrm{ABC})$ transporters are known to play a major role in drug absorption, distribution, and excretion, including influencing the CNS accumulation of pharmacological substances. Recently Cotte and colleagues have reported that the expression of ABC-gene single nucleotide polymorphisms (SNPs) in MS patients may be predictive of clinical responses to mitoxantrone and also of possible susceptibility to some cardiac adverse events [Cotte et al. 2009]. Related to this, a recent case report from Dörr and coworkers was the first description of a completely reversible, clinically relevant, and almost fatal, mitoxantrone-related cardiotoxicity (congestive heart failure) in a young RRMS patient without pre-existing cardiac disease or preceding cardiotoxic treatment. The authors hypothesize that the development of toxic cardiomyopathy shortly after a second course of mitoxantrone treatment might have resulted from increased mitoxantrone exposure due to the combination of two SNPs in the ABCB1 gene and one SNP in the ABCG2 gene [Dörr et al. 2009].

Such data, if confirmed, raise the possibility of optimizing individual risk-benefit profiles based on pharmacogenetic markers of effect: for example, individualized dose titration, intervals, and safety monitoring [Cotte et al. 2009]. This would be of particular value for an agent such as mitoxantrone, which although an approved treatment, is a relatively high-risk therapeutic option requiring close monitoring and management.

\section{Efficacy of mitoxantrone induction chemotherapy}

Although not approved, a regimen involving a brief (few months) induction treatment with mitoxantrone, followed by long-term maintenance therapy with either IFN $\beta$ or GA, has recently received considerable attention for the treatment of MS [Le Page and Edan, 2009; Arnold et al. 2008; Le Page et al. 2008; Vollmer et al. 2008]. Proponents of this approach believe that induction with an immunosuppressive agent may modify the immunologic mechanisms at play and limit the ongoing inflammatory process, allowing subsequent immunomodulatory maintenance therapy to prevent or limit further inflammation. Relatively small studies have indicated that induction with mitoxantrone followed by an IFN $\beta 1 \mathrm{a}, \operatorname{IFN} \beta 1 \mathrm{~b}$, or GA maintenance treatment may provide superior disease control (in terms of reduced relapse rates and lesions on MRI) to monotherapy with IFN $\beta$ or GA [Le Page and Edan, 2009; Arnold et al. 2008; Le Page et al. 2008; Vollmer et al. 2008; Zaffaroni et al. 2008; Jeffery et al. 2005]. Present data suggest that this therapeutic approach may be most suitable in patients with particularly aggressive disease characterized by poor prognostic factors, such as a larger number or volume of lesions on MRI, incomplete recovery from relapses, and frequent early relapses. Ultimately, it seems prudent to restrict mitoxantrone use in patients with early stages of MS to those with particularly aggressive disease, given the potential cardiotoxicity and secondary leukemia.

\section{Azathriopine}

Not approved for MS treatment in the United States, but licensed for MS therapy in Germany, azathioprine was discovered in the mid-1950s. It is a purine analog that is metabolized rapidly to the cytotoxic and immunosuppressant derivatives 6-mercaptopurine and thioinosine acid. It mainly targets activation, proliferation, and differentiation of both $\mathrm{T}$ and $\mathrm{B}$ lymphocytes through the competition of its metabolites with DNA nucleotides [Casetta et al. 2007]. Despite not being approved for MS treatment in the United States, there has been off-label use of azathioprine to treat MS for more than 30 years. In 2007, the Cochrane Collaboration conducted a systematic review of the efficacy of azathioprine in the treatment of MS [Casetta et al. 2007]. The researchers included only randomized, placebo-controlled trials that lasted at least 1 year. Five trials, including a total of $698 \mathrm{MS}$ patients, met the criteria for inclusion in the review. The meta-analysis indicated that azathioprine reduced relapses during the first, second, and third years of follow-up, and reduced disease progression during the first 2-3 years. In addition, the findings from a randomized controlled study comparing azathioprine with IFN $\beta$ in 94 patients with RRMS suggested that this drug may be as effective as IFN $\beta$ in reducing relapses and decreasing disability progression as measured by EDSS [Etemadifar et al. 2007]. The safety profile of azathioprine appears to be more favorable than the profiles of mitoxantrone or cyclophosphamide. It is associated with gastrointestinal 
disturbances, bone marrow suppression, and hepatic toxicity, but these concerns can be effectively managed with careful monitoring and attention to dose adjustments [Casetta et al. 2007]. The major safety concern with chronic azathioprine treatment is the increased risk of non-Hodgkin lymphoma or other malignancies during long-term use (i.e. after approximately 5-10 years) [Confavreux et al. 1996; Lhermitte et al. 1984]. Evidence indicates that this risk may be dose related and significant with cumulative doses $>600 \mathrm{~g}$ [Casetta et al. 2007]. Azathioprine should not be administered to the approximately 1 in 300 individuals with thiopurine S-methyltransferase deficiency, an autosomal recessive trait causing excessive thioguanine nucleotide accumulation in hematopoietic tissues which can result in severe and possibly fatal myelosuppression [Yates et al. 1997]. As with mitoxantrone, azathioprine is typically reserved for those with an inadequate response to first-line therapy because of safety concerns.

\section{Chemotherapies not approved for multiple sclerosis, but used in clinical practice}

In addition to the indicated use of mitoxantrone, other chemotherapeutic agents are used off-label for the treatment of MS.

\section{Cyclophosphamide}

Cyclophosphamide is a cytotoxic, alkylating agent related to nitrogen mustards. The active metabolites of cyclophosphamide induce DNA string breaks. In addition to mediating powerful immunosuppression, cyclophosphamide can also exert immunomodulatory effects by shifting immune responses from Th1 cells toward Th2 cells, by an as yet unknown mechanism [Weiner and Cohen, 2002]. Cyclophosphamide has been used extensively in various inflammatory disorders, including MS, despite the fact that efficacy results have been inconsistent. The only two prospective, blinded, placebo-controlled, randomized trials of cyclophosphamide monotherapy failed to show benefits [Likosky et al. 1991; The Canadian Cooperative Multiple Sclerosis Study Group, 1991]. It should be noted that the population of patients studied in these trials contained a high proportion of patients with late SPMS and primary progressive MS (PPMS). In the absence of inflammatory disease activity, it is not surprising that a benefit was not apparent. In populations of patients with active inflammatory disease, cyclophosphamide appears effective as a rescue therapy [Gladstone et al. 2006; Smith, 2004; Khan et al. 2001]. Some evidence of efficacy has emerged from controlled, but unblinded trials, but the available data do not allow any definitive conclusions to be made concerning the efficacy of cyclophosphamide monotherapy [Weiner et al. 1993; Goodkin et al. 1987; Hauser et al. 1983]. Although well-designed trials have failed to conclusively demonstrate the efficacy of cyclophosphamide monotherapy, it is possible that combining cyclophosphamide, IFN $\beta$, and other agents may be an option for patients failing previous therapy and with limited treatment options. Data from a randomized, single-blinded, placebo-controlled, multicenter trial combining monthly cyclophosphamide and corticosteroids with IFN $\beta$ indicate that this combination has some efficacy in reducing clinical relapses and MRI lesions [Smith et al. 2005].

A major concern with cyclophosphamide therapy is the adverse event profile, which has been reported to lead, in rare instances, to fatalities. Frequent, nonfatal side effects include mild to moderate alopecia (which may be total), infertility, nausea, amenorrhea, and infections. It is also less frequently associated with hemorrhagic cystitis, bladder cancer, leukemia, and possibly other cancers. Cyclophosphamide is also a teratogen [Cyclophosphamide US prescribing information, 2009]. As with mitoxantrone, cyclophosphamide is generally only administered under the direction of physicians experienced in the use of cytotoxic or immunosuppressant therapies. Regular bloodcell counts are required in patients receiving cyclophosphamide. Aggressive hydration can minimize cystitis, and bladder cancer screening should be considered with chronic use [Cyclophosphamide US prescribing information, 2009]. Owing to its potentially harmful side effects and the lack of proven efficacy in controlled studies, cyclophosphamide use only appears appropriate in aggressive MS variants unresponsive to standard immunomodulatory therapy and natalizumab.

\section{Methotrexate}

Methotrexate is an antimetabolite that inhibits dihydrofolic acid reductase. Dihydrofolate reduction to tetrahydrofolate is necessary before its action as a carrier of one-carbon groups in the synthesis of purine nucleotides and thymidylate. Mechanistically, therefore, methotrexate interferes with DNA synthesis, repair, and cellular replication [Methotrexate US prescribing 
information, 2009]. Exactly how methotrexate mediates benefits in autoimmune diseases such as MS remains elusive.

In the United States, methotrexate is approved for the management of rheumatoid arthritis, gestational choriocarcinoma, chorioadenoma destruens, hydatidiform mole, meningeal leukemia, advanced stage non-Hodgkin lymphomas, and for the treatment of a variety of other malignancies [Methotrexate US prescribing information, 2009]. Long-term methotrexate administration is associated with serious side effects, including hepatic fibrosis [Gray et al. 2006], and additional serious toxic reactions that can be fatal. As a consequence, patients receiving chronic treatment with methotrexate should be monitored for bone marrow, liver, lung, and kidney toxicities [Methotrexate US prescribing information, 2009]. Unexpectedly severe, sometimes fatal, gastrointestinal toxicity has been reported with concomitant administration of methotrexate and some nonsteroidal anti-inflammatory drugs. Therapy must be interrupted for diarrhea and ulcerative stomatitis, otherwise, hemorrhagic enteritis and death from intestinal perforation may occur. Severe, occasionally fatal, skin reactions have been reported following single or multiple doses of methotrexate, and potentially fatal opportunistic infections have also been reported recorded [Methotrexate US prescribing information, 2009]. Evidence to date suggests that at the doses currently used in MS, methotrexate toxicity generally remains minimal as long as methotrexate treatment is accompanied by concomitant folate substitution [Gray et al. 2006]. A systematic review published by the Cochrane Collaboration in 2004 concluded that in PRMS, patients receiving methotrexate had a nonsignificant trend towards reduction of EDSS progression and relapses [Gray et al. 2004]. Such findings point to inconclusive evidence of efficacy in PRMS, and there are no sufficiently welldesigned trials to ascertain the effectiveness of methotrexate monotherapy in RRMS. More recently, the randomized Avonex Combination Trial (ACT), which included 313 patients with RRMS, found no significant benefit of adding low-dose methotrexate to treatment in patients with ongoing disease activity while receiving IFN $\beta$-1a monotherapy [Cohen et al. 2009]. Taken together, these findings suggest that methotrexate is likely to have only a limited role in MS management and therefore should not be used as a substitute for currently approved therapies.
The next generation of chemotherapeutic agents in multiple sclerosis

In addition to the anticancer agents discussed above, other therapeutics that are currently licensed for the management of malignancies have recently been investigated for efficacy in MS. These include cladribine, alemtuzumab, and rituximab.

\section{Cladribine}

Cladribine is an adenosine deaminase-resistant nucleoside analog that ablates subpopulations of lymphocytes. As an active triphosphate analog, cladribine triphosphate becomes incorporated into DNA of dividing cells, leading to DNA damage and subsequent cell death. Currently, cladribine is an approved treatment for hairycell leukemia and lymphoma. However, its long-lasting lymphocytotoxic activity suggests that it could be useful in modulating conditions involving chronic lymphocyte abnormalities, including MS. In MS, cladribine has been assessed in both subcutaneous (SC) and oral formulations. Relatively small phase I and II placebo-controlled trials of subcutaneously administered cladribine in chronic PRMS and RRMS revealed encouraging findings that were underlined by encouraging MRI benefits, for example, nearly complete elimination of enhanced $\mathrm{T} 1$ lesions and stabilization of $\mathrm{T} 2$ lesion volumes [Romine et al. 1999; Beutler et al. 1996; Sipe et al. 1994]. However, although these smaller studies raised expectations, a multicenter, double-blind, placebo-controlled, phase III study of subcutaneously administered cladribine in 159 patients with SPMS and PRMS failed to show significant clinical or MRI benefits after 1 year [Filippi et al. 2000a, 2000b; Rice et al. 2000]. An oral formulation of cladribine has also been developed and has recently been evaluated in a phase III clinical trial [Comi et al. 2009; Cook et al. 2009; Vermersch et al. 2009]. Following encouraging data from small pilot investigations, this 96-week, randomized, double-blind, placebo-controlled, phase III study, CLARITY, was initiated in 1326 patients with active inflammatory RRMS [Giovannoni et al. 2010].

In the study, $10 \mathrm{mg}$ cladribine or placebo was given orally over 5 days per month, administered in 4 or 6 cycles per year (cumulative dose of $3.5 \mathrm{mg} / \mathrm{kg}$ or $5.25 \mathrm{mg} / \mathrm{kg}$ ). Oral cladribine was associated with relative reductions in ARR of $55-58 \%$ (0.14- 0.15 cladribine groups 
vs. 0.33 placebo), a reduction in the risk of 3 -month disability progression of $31-33 \%$ (from hazard ratios), and a reduction in gadolinium-enhanced $(\mathrm{Gd}+)$ lesions per patient, per scan of $86-88 \%$ (mean number $0.11-0.12$ cladribine groups versus 0.91 placebo) [Giovannoni et al. 2010]. Cladribine treatment reduced the cumulative number of relapses throughout the 96 weeks of the trial. Furthermore, cladribine treatment differentially affected CD4, CD8, and CD19 subpopulations. These findings suggest a direct effect of this agent on T-cell function, humoral B-cell activity, and antigen-presenting cell activity, which may be involved in the immune-mediated pathogenesis of MS [Rieckmann et al. 2009; Soelberg-Sorensen et al. 2009].

In terms of tolerability, the phase III trial of SC cladribine recorded upper respiratory tract infections, muscle weakness, and injection site reactions as the most common adverse events [Rice et al. 2000]. Mild herpes zoster has also been associated with SC cladribine, and one patient receiving this formulation suffered a fulminant and fatal hepatitis B infection [Sipe, 2005]. In the CLARITY trial, oral cladribine resulted in rapid and sustained decreases in lymphocyte count, with severe neutropenia reported in three patients receiving cladribine and severe thrombocytopenia and pancytopenia in one patient, who also had an exacerbation of latent tuberculosis that resulted in death [Giovannoni et al. 2010]. The incidence of infection appeared to be similar between the cladribine groups $(47.7 \%$ and $48.9 \%)$ and the placebo group (42.5\%). Adverse events reported more frequently in cladribine patients than those receiving placebo included herpes zoster and uterine leiomyomas, with 20 cladribine-treated patients developing herpes zoster infections and 5 cladribine-treated patients developing uterine leiomyomas. Compared with placebo, more patients in cladribine groups discontinued treatment because of adverse events $(5.8 \%$ versus $2.1 \%)$ and experienced serious adverse events $(8.7 \%$ versus $6.4 \%)$. Occurrence of neoplasms was reported as a serious adverse event in $1.4 \%$ of patients in the cladribine $3.5-\mathrm{mg}$ group, in $0.9 \%$ of patients in the cladribine 5.25-mg group, and in no patients in the placebo group. Although the single cases of a new neoplasm following treatment with oral cladribine were not clustered in a particular organ system, these observations may be of considerable importance. Patients treated with cladribine for hairy-cell leukemia experienced an $8 \%$ rate of secondary malignancy [Saven et al. 1998]. The tumors involved multiple organs and systems, with the gastrointestinal tract being affected most commonly.

When used for the treatment of oncologic conditions, severe bone marrow suppression, including neutropenia, anemia, and thrombocytopenia, has been commonly observed in patients treated with cladribine [Leustatin (cladribine) US prescribing information, 2009]. Obviously, cladribine prescribing information discusses hematological/ oncological indications with safety signals derived from respective studies that are not specific for MS [Leustatin (cladribine) US prescribing information, 2009]. However, although bone marrow suppression is unlikely to be as severe in patients receiving oral cladribine for MS, it is important not to forget that cladribine is a potent antineoplastic agent normally used in an acute setting, whereas treatment for MS is typically chronic. In patients receiving cladribine treatment for hairycell leukemia, analysis of lymphocyte subsets indicated that treatment with cladribine was associated with prolonged depression of CD4 counts. Prior to treatment, the mean CD4 count was $766 / \mu 1$. The mean CD4 count nadir, which occurred 4-6 months following treatment, was $272 / \mu 1$. Fifteen months after treatment, mean CD4 counts remained below 500/ $\mu$ l. CD8 counts behaved similarly, although increasing counts were observed after 9 months. The clinical significance of the prolonged CD4 lymphopenia is most likely related to infection susceptibility and decreased immune surveillance [Leustatin (cladribine) US prescribing information, 2009].

It should also be noted that, like other antineoplastic agents, cladribine is considered a teratogen, and it may also have an impact on fertility [Leustatin (cladribine) US prescribing information, 2009]. Since MS is a chronic disease, typically affecting relatively young female patients, reproductive safety and the unknown long-term effects of immunosuppression are significant concerns.

CLARITY was a controlled clinical trial, including frequent blood monitoring and patient visits, but without an active comparator agent. Hence it does not provide evidence of the relative efficacy of cladribine as compared with other potential treatment options in MS. Additional well-controlled comparative studies will be valuable in 
order to help understand the appropriate use of cladribine in the continuum of MS treatments.

The risk-benefit profile of oral cladribine use in MS is currently being further assessed in two ongoing clinical studies, and through a safety registry. The ONWARD-trial is a 96-week, randomized, double-blind, placebo-controlled, phase IIb trial in patients with active MS. This study is evaluating the safety and tolerability of oral cladribine compared with placebo as an add-on therapy to IFN $\beta$ treatments in patients with active RRMS or SPMS with superimposed relapses. Clinical endpoints and MRI criteria are secondary outcome measures in this study. The ORACLE-MS-trial is also a 96-week randomized, double blind, three-arm, placebo-controlled, multicenter, phase III trial to evaluate the safety and efficacy of oral cladribine versus placebo to prevent or delay conversion to clinically definite MS, in patients with a first clinical demyelinating event at high risk of converting to MS. Depending upon the clinical course of the MS, subjects proceed from the initial treatment period to an open-label IFN $\beta$-period or, if no progression to MS has been noted after the initial treatment period, to either open-label low-dose cladribine or no additional treatment.

It should also be noted that, in line with the other cytotoxic agents discussed in this review, the current US prescribing information for cladribine states that it should only be administered under the supervision of a qualified physician experienced in the use of antineoplastic therapy [Leustatin (cladribine) US prescribing information, 2009].

\section{Alemtuzumab}

Alemtuzumab is a humanized $\mathrm{mAb}$ directed against the CD52 antigen expressed on the cell surface of both T and B lymphocytes, monocytes, macrophages, and eosinophils, but not stem cells. It depletes target antigen carrying cells, leading to rapid removal of $\mathrm{T}$ cells from blood, bone marrow, and organs. This T-cell depletion lasts for up to 16 months. It is FDA approved for the treatment of refractory chronic lymphocytic leukemia [Linker and Kieseier, 2008]. As a consequence of promising results from initial trials of alemtuzumab in patients with MS [Coles et al. 2006, 1999; Paolillo et al. 1999], a phase II, randomized, open-label study was initiated to compare alemtuzumab with IFN $\beta-1$ a in 334 patients with early RRMS [CAMMS223 Trial investigators, 2008]. The trial was interrupted in 2005 because of three unexpected cases of idiopathic thrombocytopenia purpura (ITP), including two fatalities, and efficacy and safety results from the trial have been reported [CAMMS223 Trial investigators, 2008]. The trial found significant efficacy of this $\mathrm{mAb}$ in reducing sustained disability and reducing ARRs, as well as in providing improvements in MRI outcomes. However, alemtuzumab was associated with problematic side effects. Thyroid autoimmunity occurred in nearly $25 \%$ of treated patients (versus 3\% with IFN $\beta$ ), and ITP was seen in nearly $3 \%$ of patients receiving alemtuzumab. One alemtuzumab patient suffered acute glomerulonephritis that required kidney transplantation. Furthermore, and as seen in oncologic use of this agent, infusion reactions with fever, rigors, rash, nausea, and hypotension occurred with alemtuzumab. There were also more infections in those patients treated with this $\mathrm{mAb}(66 \%$ vs. $47 \%$ with IFN $\beta)$. During oncologic use, alemtuzumab-related infusion reactions and infections have on rare occasions proved fatal [Campath (alemtuzumab) US prescribing information, 2009].

Following the significant efficacy seen with alemtuzumab in this study, two large multicenter phase III trials are underway (CARE I and II;

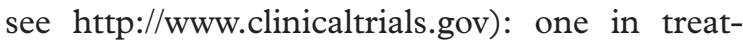
ment-naive patients, and one in patients who have failed to respond adequately to first-line treatment. These trials are of great interest given the efficacy of the drug, but also in light of the unexpected and potentially severe autoimmune side effects. Given the apparent toxicity risks associated with alemtuzumab, it remains to be seen whether this treatment will emerge as a suitable option for young adults with MS who are in the earlier stages of the disease and have little disability.

\section{Rituximab/ocrelizumab}

As noted in the pathogenesis section above, there is evidence to support the role of B cells in the development and progression of MS. Rituximab is a chimeric murine/human $\mathrm{mAb}$ that targets and selectively depletes CD20, an antigen present on pre-B cells and B cells, but not on antibody-producing plasma cells or stem cells in the bone marrow [Linker and Kieseier, 2008]. Rituximab is currently FDA approved for the treatment of non-Hodgkin lymphoma, refractory rheumatoid arthritis, and diffuse 
B-cell lymphoma. It has been given to more than 1 million patients and has well-characterized efficacy and safety profiles in these populations.

Results of a phase II randomized, placebo-controlled trial of 104 patients with RRMS showed that rituximab can lead to a significant reduction in $\mathrm{Gd}+$ lesions and relapses compared with placebo [Hauser et al. 2008]. The results from a second randomized, placebo-controlled trial in patients with PPMS have recently been reported, but unfortunately this study failed to meet its primary endpoint [Hawker et al. 2009]; overall, there was no significant difference in time to confirmed disease progression between the rituximab and placebo treatment arms. Efficacy was, however, observed versus placebo in some subgroups. Side effects of rituximab in treatment of immunological diseases primarily include infusion reactions similar to those described for alemtuzumab. Rare, but potentially severe adverse events comprise a tumor lysis syndrome, neutropenic fever, and fatal infusion reactions. These events seem more likely in tumor patients or patients that are severely immunocompromised. Cases of PML have also been observed with rituximab, including in patients with rheumatoid arthritis [Fleischmann, 2009; Rituximab (Marketed and Rituxan) Information, 2006]. However, clear interpretation of the findings from these cases is confounded by the concomitant medications used in these patients. All cases of rituximab-associated PML occurred in patients with extensive prior immunosuppressive exposure. Rituximab is a chimeric $\mathrm{mAb}$ that is approaching the end of its patent protection and has evident safety concerns, so it is unlikely to be further developed for MS. Development efforts have consequently become focused on ocrelizumab, which is a fully humanized $\mathrm{mAb}$ targeting CD20 that may offer a better safety/efficacy profile.

Ocrelizumab is currently in phase II trials for MS, with the primary trial endpoint of reduction in signs of disease activity as measured by brain lesions versus placebo. It remains to be seen if this fully humanized form provides a substantially different risk-benefit profile from rituximab.

\section{Conclusions}

Chemotherapeutic agents offer efficacy and potential convenience benefits in MS, although safety concerns remain for many of these agents. In MS, where a largely female population requires chronic treatment, risks must be weighed carefully against the benefits of each individual drug. As such, IFN $\beta$ formulations and GA are, and will remain, in place as a firstline treatment option for patients with MS. In patients with higher disease activity or breakthrough disease on first-line therapy, treatments with greater efficacy will be considered: at present, the rare safety risk for natalizumab is well known and well understood; the risks for wellestablished chemotherapeutics such as mitoxantrone, cyclophosphamide, and azathioprine are greater than those for natalizumab; and the risk profiles for the newer oncologically derived options raise some concerns and need further assessment to fully understand their potential risks. Assessing the risk-benefit ratio is becoming critical in the assessment of treatment options for the individual MS patient and must drive clinician's decision making with, and for, patients.

\section{Acknowledgement}

Simon Whiteley, $\mathrm{PhD}$, of Infusion Communications provided editorial assistance in the manuscript preparation.

\section{Funding}

This work was funded by Biogen Idec.

\section{Conflict of interest statement}

Dr Kieseier has received honoraria for lecturing, travel expenses for attending meetings, and financial support for research from Bayer Health Care, Biogen Idec, Merck Serono, Novartis, Sanofi Aventis, and TEVA. Dr Jeffery has received honoraria for speaking and consulting with Biogen Idec, Inc., Bayer, Teva, EMD Serono, Pfizer, and GSK; and receives research support from Biogen Idec, Inc., Bayer, Teva, Serono, and Pfizer.

\section{References}

Arnason, B.G., Dayal, A., Qu, Z.X., Jensen, M.A., Genç, K. and Reder, A.T. (1996) Mechanisms of action of interferon-beta in multiple sclerosis. Springer Sem Immunopathol 18: 125-148.

Arnold, D.L., Campagnolo, D., Panitch, H., Bar-Or, A., Dunn, J., Freedman, M.S. et al. (2008) Glatiramer acetate after mitoxantrone induction improves MRI markers of lesion volume and permanent tissue injury in MS. F Neurol 255: 1473-1478.

Beutler, E., Sipe, J.C., Romine, J.S., Koziol, J.A., McMillan, R. and Zyroff, J. (1996) The treatment of chronic progressive multiple sclerosis with cladribine. Proc Natl Acad Sci U S A 93: 1716-1720. 
CAMMS223 Trial Investigators, Coles, A.J., Compston, D.A., Selmaj, K.W., Lake, S.L., Moran, S., Margolin, D.H. et al. (2008) Alemtuzumab vs. interferon beta-1a in early multiple sclerosis. $N$ Engl $\mathcal{F ~ M e d ~}$ 359: 1786-1801.

Campath (alemtuzumab) US prescribing information. Last accessed 11 November 2009 berlex.bayerhealthcare.com/html/products/pi/Campath_PI.pdf.

Carrá, A., Onaha, P., Luetic, G., Burgos, M., Crespo, E., Deri, N. et al. (2008) Therapeutic outcome 3 years after switching of immunomodulatory therapies in patients with relapsing-remitting multiple sclerosis in Argentina. Eur f Neurol 15: 386-393.

Casetta, I., Iuliano, G. and Filippini, G. (2007)

Azathioprine for multiple sclerosis. Cochrane

Database Syst Rev CD003982, DOI: 10.1002/

14651858.CD003982.pub2.

Chan, A., Weilbach, F.X., Toyka, K.V. and Gold, R. (2005) Mitoxantrone induces cell death in peripheral blood leucocytes of multiple sclerosis patients. Clin Exp Immunol 139: 152-158.

Clifford, D.B., De Luca, A., Simpson, D.M., Arendt, G., Giovannoni, G. and Nath, A. (2010) Natalizumabassociated progressive multifocal leukoencephalopathy in patients with multiple sclerosis: lessons from 28 cases. Lancet Neurol 9: 438-446.

Cohen, J.A., Imrey, P.B., Calabresi, P.A., Edwards, K.R., Eickenhorst, T., Felton, W.L. et al. (2009) Results of the Avonex Combination Trial (ACT) in relapsing-remitting MS. Neurology 72: 535-541.

Coles, A.J., Wing, M.G., Molyneux, P., Paolillo, A., Davie, C.M., Hale, G. et al. (1999) Monoclonal antibody treatment exposes three mechanisms underlying the clinical course of multiple sclerosis. Ann Neurol 46: 296-304.

Coles, A.J., Cox, A., Le Page, E., Jones, J., Trip, S.A., Deans, J. et al. (2006) The window of therapeutic opportunity in multiple sclerosis: evidence from monoclonal antibody therapy. F Neurol 253: 98-108.

Comi, G., Filippi, M., Barkhof, F., Durelli, L., Edan, G., Fernández, O. et al. (2001a) Effect of early interferon treatment on conversion to definite multiple sclerosis: a randomised study. Lancet 357: 1576-1582.

Comi, G., Filippi, M. and Wolinsky, J.S. and the European/Canadian Glatiramer Acetate Study Group. (2001b) European/Canadian multicenter, doubleblind, randomized, placebo-controlled study of the effects of glatiramer acetate on magnetic resonance imaging-measured disease activity and burden in patients with relapsing multiple sclerosis. Ann Neurol 49: 290-297.

Comi, G., Cook, S., Giovannoni, G., Rammohan, K., Rieckmann, P., Sorensen, P.S. et al. (2009) Reductions in MRI activity in relapsing-remitting multiple sclerosis achieved with cladribine tablets in the 96-week, phase III, double-blind, placebo-controlled CLARITY study. Mult Scler 15(Suppl 2): S136, Abstract P469.
Confavreux, C., Saddier, P., Grimaud, J., Moreau, T., Adeleine, P. and Aimard, G. (1996) Risk of cancer from azathioprine therapy in multiple sclerosis: a case-control study. Neurology 46: 1607-1612.

Cook, S., Vermersch, P., Comi, G., Giovannoni, G., Rammohan, K., Rieckmann, P. et al. (2009) Safety and tolerability of cladribine tablets in relapsing-remitting multiple sclerosis during the 96-week, phase III, double-blind, placebo-controlled CLARITY study. Mult Scler 15(Suppl 2): S21, Abstract 88.

Cotte, S., von Ahsen, N., Kruse, N., Huber, B., Winkelmann, A., Zettl, U.K. et al. (2009) ABCtransporter gene-polymorphisms are potential pharmacogenetic markers for mitoxantrone response in multiple sclerosis. Brain 132: 2517-2530.

Cyclophosphamide US prescribing information. Last accessed 11 November 2009, http://www.mims.com/ Page.aspx?menuid $=$ mng\&CTRY $=$ US $\&$ Name $=$ Cyclophosphamide+Tablet.

Dörr, J., Bitsch, A., Schmailzl, K.J., Chan, A., von Ahsen, N., Hummel, M. et al. (2009) Severe cardiac failure in a patient with multiple sclerosis following low-dose mitoxantrone treatment. Neurology 73: 991-993.

Edan, G., Miller, D., Clanet, M., Confavreux, C., Lyon-Caen, O., Lubetzki, C. et al. (1997) Therapeutic effect of mitoxantrone combined with methylprednisolone in multiple sclerosis: a randomised multicentre study of active disease using MRI and clinical criteria. f Neurol Neurosurg Psychiatry 62: 112-118.

Ellis, R. and Boggild, M. (2009) Therapy-related acute leukaemia with mitoxantrone: what is the risk and can we minimise it? Mult Scler 15: 505-508.

Etemadifar, M., Janghorbani, M. and Shaygannejad, V. (2007) Comparison of interferon beta products and azathioprine in the treatment of relapsing-remitting multiple sclerosis. F Neurol 254: 1723-1728.

Fernandez, O. (2007) Combination therapy in multiple sclerosis. F Neurol Sci 259: 95-103.

Filippi, M., Rovaris, M., Iannucci, G., Mennea, S., Sormani, M.P. and Comi, G. (2000a) Whole brain volume changes in patients with progressive MS treated with cladribine. Neurology 55: 1714-1718.

Filippi, M., Rovaris, M., Rice, G.P., Sormani, M.P., Iannucci, G., Giacomotti, L. et al. (2000b) The effect of cladribine on T(1) 'black hole' changes in progressive MS. F Neurol Sci 176: 42-44.

Fleischmann, R.M. (2009) Progressive multifocal leukoencephalopathy following rituximab treatment in a patient with rheumatoid arthritis. Arthritis Rheum 60: 3225-3228.

Ghalie, R.G., Mauch, E., Edan, G., Hartung, H.P., Gonsette, R.E., Eisenmann, S. et al. (2002) A study of therapy-related acute leukaemia after mitoxantrone therapy for multiple sclerosis. Mult Scler 8: 441-445.

Gilden, D.H. (2005) Infectious causes of multiple sclerosis. Lancet Neurol 4: 195-202. 
Giovannoni, G., Comi, G., Cook, S., Rammohan, K., Rieckmann, P., Sorensen, P.S. et al. (2010) A placebocontrolled trial of oral cladribine for relapsing multiple sclerosis. N Engl f Med 362: 416-426.

Gladstone, D.E., Zamkoff, K.W., Krupp, L., Peyster, R., Sibony, P., Christodoulou, C. et al. (2006) Highdose cyclophosphamide for moderate to severe refractory multiple sclerosis. Arch Neurol 63: 1388-1393.

Gold, R. (2008) Combination therapies in multiple sclerosis. F Neurol 255(Suppl 1): 51-60.

Gonsette, R.E. (2008) Oxidative stress and excitotoxicity: a therapeutic issue in multiple sclerosis. Mult Scler 14: 22-34.

Goodkin, D.E., Plencner, S., Palmer-Saxerud, J., Teetzen, M. and Hertsgaard, D. (1987)

Cyclophosphamide in chronic progressive multiple sclerosis: maintenance vs nonmaintenance therapy. Arch Neurol 44: 823-827.

Gray, O., McDonnell, G.V. and Forbes, R.B. (2004) Methotrexate for multiple sclerosis. Cochrane Database Syst Rev 2: CD003208.

Gray, O.M., McDonnell, G.V. and Forbes, R.B. (2006) A systematic review of oral methotrexate for multiple sclerosis. Mult Scler 12: 507-510.

Hartung, H.P., Gonsette, R., König, N., Kwiecinski, H., Guseo, A., Morrissey, S.P. et al. (2002) Mitoxantrone in Multiple Sclerosis Study Group (MIMS). Mitoxantrone in progressive multiple sclerosis: a placebo-controlled, double-blind, randomised, multicentre trial. Lancet 360: 2018-2025.

Hauser, S., Dawson, D., Lehrich, J., Beal, M.F., Kevy, S.V., Propper, R.D. et al. (1983) Intensive immunosuppression in progressive multiple sclerosis: a randomized, three-arm study of high-dose intravenous cyclophosphamide, plasma exchange, and ACTH. N Engl f Med 308: 173-180.

Hauser, S.L., Waubant, E., Arnold, D.L., Vollmer, T., Antel, J., Fox, R.J. et al. (2008) B-cell depletion with rituximab in relapsing-remitting multiple sclerosis. $N$ Engl f Med 358: 676-688.

Hawker, K., O'Connor, P., Freedman, M.S., Calabresi, P.A., Antel, J., Simon, J. et al. (2009) Rituximab in patients with primary progressive multiple sclerosis: results of a randomized double-blind placebo-controlled multicenter trial. Ann Neurol 66: 460-471.

Hutchinson, M., Kappos, L., Calabresi, P.A., Confavreux, C., Giovannoni, G., Galetta, S.L. et al. (2009) The efficacy of natalizumab in patients with relapsing multiple sclerosis: subgroup analyses of AFFIRM and SENTINEL. F Neurol 256: 405-415.

Jacobs, L.D., Cookfair, D.L., Rudick, R.A., Herndon, R.M., Richert, J.R., Salazar, A.M. et al. (1996) The Multiple Sclerosis Collaborative Research Group (MSCRG). Intramuscular interferon beta-1a for disease progression in relapsing multiple sclerosis. Ann Neurol 39: 285-294.
Jeffery, D.R., Chepuri, N., Durden, D. and Burdette, J. (2005) A pilot trial of combination therapy with mitoxantrone and interferon beta-1b using monthly gadolinium-enhanced magnetic resonance imaging. Mult Scler 11: 296-301.

Johnson, K.P., Brooks, B.R., Cohen, J.A., Ford, C.C., Goldstein, J., Lisak, R.P. et al. (1995) The Copolymer 1 Multiple Sclerosis Study Group. Copolymer 1 reduces relapse rate and improves disability in relapsing-remitting multiple sclerosis: results of a phase III multicenter, double-blind placebo-controlled trial. Neurology 45: 1268-1276.

Kappos, L., Polman, C.H., Freedman, M.S., Edan, G., Hartung, H.P., Miller, D.H. et al. (2006)

Treatment with interferon beta-1b delays conversion to clinically definite and McDonald MS in patients with clinically isolated syndromes. Neurology

67: 1242-1249.

Kappos, L., Freedman, M.S., Polman, C.H., Edan, G., Hartung, H.P., Miller, D.H. et al. (2007) Effect of early versus delayed interferon beta- $1 \mathrm{~b}$ treatment on disability after a first clinical event suggestive of multiple sclerosis: a 3-year follow-up analysis of the BENEFIT study. Lancet 370: 389-397.

Khan, O.A., Zvartau-Hind, M., Caon, C., Din, M.U., Cochran, M., Lisak, D. et al. (2001) Effect of monthly intravenous cyclophosphamide in rapidly deteriorating multiple sclerosis patients resistant to conventional therapy. Mult Scler 7: 185-188.

Kieseier, B.C., Putzki, N., Bates, D., Hutchinson, M., Pace, A. and Hyde, R. (2009) Improvement in qualityof-life outcomes with natalizumab in multiple sclerosis patients with highly active disease. Neurology 72(Suppl 3): A238.

Kinkel, R.P., Kollman, C., O’Connor, P., Murray, T.J., Simon, J., Arnold, D. et al. (2006) IM interferon beta1a delays definite multiple sclerosis 5 years after a first demyelinating event. Neurology 66: 678-684.

Kopadze, T., Dehmel, T., Hartung, H.P., Stüve, O. and Kieseier, B.C. (2006) Inhibition by mitoxantrone of in vitro migration of immunocompetent cells: a possible mechanism for therapeutic efficacy in the treatment of multiple sclerosis. Arch Neurol 63: 1572-1578.

Krapf, H., Morrissey, S.P., Zenker, O., Zwingers, T., Gonsette, R. and Hartung, H.P. for the MIMS Study Group. (2005) Effect of mitoxantrone on MRI in progressive MS: results of the MIMS trial. Neurology 65: 690-695.

Le Page, E., Leray, E., Taurin, G., Coustans, M., Chaperon, J., Morrissey, S.P. et al. (2008)

Mitoxantrone as induction treatment in aggressive relapsing remitting multiple sclerosis: treatment response factors in a 5 year follow-up observational study of 100 consecutive patients. $\mathcal{F}$ Neurol Neurosurg Psychiatry 79: 52-56.

Le Page, E. and Edan, G. (2009) Long-term experience with induction treatment regimens 
in multiple sclerosis. $\mathcal{F}$ Neurol Sci 277(Suppl 1): S46-S49.

Leustatin (cladribine) US prescribing information. Last accessed 11 November 2009, http:/www.orthobiotech.com/orthobiotech/shared/OBI/PI/

Leustatin_PI.pdf.

Lhermitte, F., Marteau, R. and Roullet, E. (1984) Not so benign long-term immunosuppression in multiple sclerosis. Lancet 1: 276-277.

Likosky, W.H., Fireman, B., Elmore, R., Eno, G., Gale, K., Goode, G.B. et al. (1991) Intense immunosuppression in chronic progressive multiple sclerosis: the Kaiser study. $\mathcal{F}$ Neurol Neurosurg Psychiatry 54: 1055-1060.

Linker, R. and Kieseier, B.C. (2008) Innovative therapy with monoclonal antibodies in multiple sclerosis. Ther Adv Neurol Disord 1: 33-42.

Markowitz, C.E. (2007) Interferon-beta: mechanism of action and dosing issues. Neurology 68(24 Suppl 4): S8-S11.

Marriott, J.J., Miyasaki, J.M., Gronseth, G. and O'Connor, P.W. (2010) Evidence Report: The efficacy and safety of mitoxantrone (Novantrone) in the treatment of multiple sclerosis. Neurology 74: 1463-1470.

Martinelli, V. (2009) Leukemia risk with Mitoxantrone for multiple sclerosis. American Academy of Neurology 61st Annual Meeting, Seattle, WA, 25 April-2 May 2009. Abstract LB3.001.

Methotrexate US prescribing information. Last accessed 11 November 2009, http://www.mims.com/ Page aspx ?menuid $=$ mng\&CTRY $=\mathrm{US} \&$ Name $=$ Methotrexate+Injection $\% 2 \mathrm{C}+$ Solution.

Millefiorini, E., Gasperini, C., Pozzilli, C., D’Andrea, F., Bastianello, S., Trojano, M. et al. (1997)

Randomized placebo-controlled trial of mitoxantrone in relapsing-remitting multiple sclerosis: 24-month clinical and MRI outcome. 7 Neurol 244: 153-159.

Morrissey, S.P., Le Page, E. and Edan, G. (2005) Mitoxantrone in the treatment of multiple sclerosis. Int Mult Scler F 12: 74-87.

Neuhaus, O., Wiendl, H., Kieseier, B.C., Archelos, J.J, Hemmer, B., Stüve, O. et al. (2005) Multiple sclerosis: mitoxantrone promotes differential effects on immunocompetent cells in vitro. $\mathcal{F}$ Neuroimmunol 168: 128-137.

Neuhaus, O., Kieseier, B.C. and Hartung, H.P. (2006) Therapeutic role of mitoxantrone in multiple sclerosis. Pharmacol Ther 109: 198-209.

Noseworthy, J.H., Lucchinetti, C., Rodriguez, M. and Weinshenker, B.G. (2000) Multiple sclerosis. N Engl f Med 343: 938-952.

Novantrone (mitoxantrone) US prescribing information. Last accessed 9 November 2009, http://www.novantrone.com/assets/pdf/novantrone_prescribing_info. pdf.
Paolillo, A., Coles, A.J., Molyneux, P.D., Gawne-Cain, M., MacManus, D., Barker, G.J. et al. (1999) Quantitative MRI in patients with secondary progressive MS treated with monoclonal antibody Campath 1H. Neurology 53: 751-757.

Platten, M. and Steinman, L. (2005) Multiple sclerosis: trapped in deadly glue. Nat Med 11: 252-253.

Polman, C.H., O’Connor, P.W., Havrdova, E., Hutchinson, M., Kappos, L., Miller, D.H. et al. (2006) A randomized, placebo-controlled trial of natalizumab for relapsing multiple sclerosis. $N \mathrm{Engl} \mathcal{F ~} \mathrm{Med}$ 354: 899-910.

PRISMS (Prevention of Relapses and Disability by Interferon beta-1a Subcutaneously in Multiple Sclerosis) Study Group (1998) Randomised doubleblind placebo-controlled study of interferon beta-1a in relapsing/remitting multiple sclerosis. Lancet 352: 1498-1504.

Racke, M.K. (2008) The role of B cells in multiple sclerosis: rationale for B-cell-targeted therapies. Curr Opin Neurol 21(Suppl 1): S9-S18.

Racke, M.K., Lovett-Racke, A.E. and Karandikar, N.J. (2010) The mechanism of action of glatiramer acetate treatment in multiple sclerosis. Neurology 74(Suppl 1): S25-S30.

Rejdak, K., Petzold, A., Stelmasiak, Z. and Giovannoni, G. (2008) Cerebrospinal fluid brain specific proteins in relation to nitric oxide metabolites during relapse of multiple sclerosis. Mult Scler 14: 59-66.

Rice, G.P., Filippi, M. and Comi, G. (2000) Cladribine and progressive MS: clinical and MRI outcomes of a multicenter controlled trial. Cladribine MRI Study Group. Neurology 54: 1145-1155.

Rieckmann, P., Comi, G., Cook, S., Giovannoni, G., Rammohan, K., Sorensen, P.S. et al. (2009) Effects of cladribine tablets on peripheral lymphocyte subtypes implicated in multiple sclerosis immunopathogenesis: surface marker analysis for a subset of patients from the 96-week, phase III, double-blind, placebo-controlled CLARITY study. Mult Scler 15(Suppl 2): S248, Abstract P816.

Rituximab (Marketed and Rituxan) Information (2006) US Food and Drug Administration Center for Drug Evaluation and Research, US Department of Health and Human Services: Rockville, MD.

Romine, J.S., Sipe, J.C., Koziol, J.A., Zyroff, J. and Beutler, E. (1999) A double-blind, placebo-controlled, randomized trial of cladribine in relapsing-remitting multiple sclerosis. Proc Assoc Am Physicians 111: 35-44.

Rudick, R.A., Stuart, W.H., Calabresi, P.A., Confavreux, C., Galetta, S.L., Radue, E.W. et al. (2006) Natalizumab plus interferon beta-1a for relapsing multiple sclerosis. N Engl f Med 354: 911-923.

Saven, A., Burian, C., Koziol, J.A. and Piro, L.D. (1998) Long-term follow-up of patients with hairy cell 
leukemia after cladribine treatment. Blood 92: 1918-1926.

Sipe, J.C., Romine, J.S., Koziol, J.A., McMillan, R., Zyroff, J. and Beutler, E. (1994) Cladribine in treatment of chronic progressive multiple sclerosis. Lancet 344: 9-13.

Sipe, J.C. (2005) Cladribine for multiple sclerosis: review and current status. Expert Rev Neurother 5: $721-727$.

Smith, D. (2004) Preliminary analysis of a trial of pulse cyclophosphamide in IFN-beta-resistant active MS. J Neurol Sci 223: 73-79.

Smith, D.R., Weinstock-Guttman, B., Cohen, J.A., Wei, X., Gutmann, C., Bakshi, R. et al. (2005) A randomized, blinded trial of combination therapy with cyclophosphamide in patients with active MS on interferon-beta. Mult Scler 11: 573-582.

Soelberg-Sorensen, P., Comi, G., Cook, S., Giovannoni, G., Rammohan, K., Rieckmann, P. et al. (2009) Effects of cladribine tablets on haematological profiles in patients with relapsing-remitting multiple sclerosis in the 96-week, phase III, double-blind, placebo-controlled CLARITY study. Mult Scler 15(Suppl 2): S137, Abstract P472.

The Canadian Cooperative Multiple Sclerosis Study Group (1991) The Canadian cooperative trial of cyclophosphamide and plasma exchange in progressive multiple sclerosis. Lancet 337: 441-446.

The IFNB Multiple Sclerosis Study Group and the University of British Columbia MS/MRI Analysis Group (1995) Interferon beta-1b in the treatment of multiple sclerosis: final outcome of the randomized controlled trial. Neurology 45: 1277-1285.

The International Multiple Sclerosis Genetics Consortium (2007) Risk alleles for multiple sclerosis identified by a genomewide study. $N \mathrm{Engl} \mathcal{F} \mathrm{Med}$ 357: $851-862$.

van Boxel-Dezaire, A.H., Hoff, S.C., van Oosten, B.W., Verweij, C.L., Dräger, A.M., Adèr, H.J. et al. (1999) Decreased interleukin-10 and increased interleukin-12p40 mRNA are associated with disease activity and characterize different disease stages in multiple sclerosis. Ann Neurol 45: 695-703.

van de Wyngaert, F.A., Beguin, C., D'Hooghe, M.B., Dooms, G., Lissoir, F., Carton, H. et al. (2001) A double-blind clinical trial of mitoxantrone versus methylprednisolone in relapsing, secondary progressive multiple sclerosis. Acta Neurol Belg 101: 210-216.

Vartanian, T. (2003) An examination of the results of the EVIDENCE, INCOMIN, and phase III studies of interferon beta products in the treatment of multiple sclerosis. Clin Ther 25: 105-118.

Vermersch, P., Comi, G., Cook, S., Giovannoni, G., Rammohan, K., Rieckmann, P. et al. (2009) Early onset of effect of treatment with cladribine tablets for relapsing-remitting multiple sclerosis in the 96-week, phase III, double-blind, placebocontrolled CLARITY study. Mult Scler 15(Suppl 2): S249, Abstract P817.

Vollmer, T., Panitch, H., Bar-Or, A., Dunn, J., Freedman, M.S., Gazda, S.K. et al. (2008) Glatiramer acetate after induction therapy with mitoxantrone in relapsing multiple sclerosis. Mult Scler 14: 663-670.

Weiner, H.L. and Cohen, J.A. (2002) Treatment of multiple sclerosis with cyclophosphamide: critical review of clinical and immunologic effects. Mult Scler 8: $142-154$.

Weiner, H.L., Mackin, G.A., Orav, E.J., Hafler, D.A., Dawson, D.M., La Pierre, Y. et al. (1993) Intermittent cyclophosphamide pulse therapy in progressive multiple sclerosis: final report of the Northeast Cooperative Multiple Sclerosis Treatment Group. Neurology 43: 910-918.

Yates, C.R., Krynetski, E.Y., Loennechen, T., Fessing, M.Y., Tai, H.L., Pui, C.H. et al. (1997) Molecular diagnosis of thiopurine S-methyltransferase deficiency: genetic basis for azathioprine and mercaptopurine intolerance. Ann Intern Med 126: 608-614.

Yong, V.W., Chabot, S., Stuve, O. and Williams, G. (1998) Interferon beta in the treatment of multiple sclerosis: mechanisms of action. Neurology 51: 682-689.

Zaffaroni, M., Rizzo, A., Baldini, S.M., Ghezzi, A. and Comi, G. (2008) Induction and add-on therapy with mitoxantrone and interferon beta in multiple sclerosis. Neurol Sci 29(Suppl 2): S230-S232.

Zipoli, V., Portaccio, E., Hakiki, B., Siracusa, G., Sorbi, S. and Amato, M.P. (2008) Intravenous mitoxantrone and cyclophosphamide as second-line therapy in multiple sclerosis: an open-label comparative study of efficacy and safety. $\mathcal{F}$ Neurol Sci 266: 25-30.
Visit SAGE journals online http://tan.sagepub.com

(SAGEJOURNALS 